where $R$ is an arbitrary function of $v$ and $c$ an arbitrary constant, not zero. Whittemore's equations $\left(1^{\prime \prime}\right)$, taken in conjunction with his relation (6), are reducible to this form.

HaRvard University

\title{
THE DIFFERENTIATION OF A FUNCTION OF A FUNCTION
}

BY H. S. CARSLAW

The reviewer of Rothe's interesting work Vorlesungen über Höhere Mathematik (1921) in this BULLETIN (vol. 28, p. 468) calls attention to the author's tentative claim that the first valid proof of the formula for the derivative of a function of a function is to be found therein, and he mentions the careful treatment of the question in Pierpont's Theory of Functions of a Real Variable (1905).

It is perhaps worth while to notice that Dini in his Lezioni di Analisi Infinitesimale (autographed edition, 1877) and Genocchi-Peano in their Calcolo Differenziale (1884) both gave satisfactory proofs. The treatment of Genocchi-Peano is cited and reproduced by Stolz in Grundzüge der Differentialund Integralrechnung, Bd. I (1893).

A proof on the same lines as that of Pierpont was given by Tannery in his Introduction à la Théorie des Fonctions d'une Variable (1886). See also Cesàro's Lehrbuch der Algebraischen Analysis und der Infinitesimalrechnung, Deutsch von Kowalewski (1904), and Kowalewski's Grundzüge der Differential-und Integralrechnung (1909).

It is remarkable that even the most careful English writers on the calculus have missed the defect in the proof to be found in our standard works on that subject.

The University of Sydney, Australia 